\title{
ecology
}

\section{The first use of Fulton's $K$ for assessing and comparing the conditions of intertidal fish populations}

\begin{tabular}{|r|l|}
\hline Journal: & Marine Ecology \\
\hline Manuscript ID: & MAE-2026 \\
\hline Manuscript Type: & Regular Paper \\
\hline Date Submitted by the Author: & 09-Feb-2014 \\
\hline Complete List of Authors: & $\begin{array}{l}\text { Barrett, Chris; Cefas, Applied Fisheries Science \& Technology } \\
\text { Johnson, Magnus; University of Hull, CEMS } \\
\text { Hull, Sue; University of Hull, CEMS }\end{array}$ \\
\hline Keywords: & $\begin{array}{l}\text { Condition, lipophrys pholis, taurulus bubalis, intertidal, rocky shore, } \\
\text { Fulton's K }\end{array}$ \\
\hline \multicolumn{2}{|c}{} \\
\hline
\end{tabular}

SCHOLARONE ${ }^{m}$

Manuscripts

This is the peer reviewed version of the following article: Barrett, C. J., Johnson, M. L., Hall, N. J. and Hull, S. L. (2016), The first use of Fulton's K for assessing and comparing the conditions of inter-tidal fish populations. Mar Ecol, 37: 42-45., which has been published in final form at http://onlinelibrary.wiley.com/doi/10.1111/maec.12234/abstract. This article may be used for non-commercial purposes in accordance with Wiley Terms and Conditions for Self-Archiving. 
1

2

3

4

5

6

7

8

9

10

11

12

13

14

15

16

17

18

19

20

21

22

23

24

25

26

27

28

29

30

31

32

33

34

35

36

37

38

39

40

41

42

43

44

45

46

47

48

49

50

51

52

53

54

55

56

57

58

59

60
8 Abstract

9 Fulton's K condition factor was applied, for the first time, to intertidal specimens of the

\section{The first use of Fulton's $\mathrm{K}$ for assessing and comparing the conditions of intertidal fish}

populations

Barrett, C.J ${ }^{a}$, Johnson, M.L ${ }^{b}$. , Hull, S. $L^{b}$.

${ }^{a}$ Cefas, Pakefield Road, Lowestoft, Suffolk, U.K., NR33 OHT.

${ }^{b}$ CEMS, University of Hull, Filey Road, Scarborough, U.K., YO11 3AZ

shanny (Lipophrys pholis) and long-spined scorpion fish (Taurulus bubalis) from two English

rocky shore, and two Welsh rocky shore sites, during summer 2010 and winter 2011. As

both species contribute to the diet of commercial species such as cod (Gadus morhua) and

endangered species such as the sea otter (Enhydra lutris), their condition may affect that of

said predators. Fulton's K found that intertidal Welsh fish maintained a 'good' condition

between seasons, while the intertidal English fish were in a poorer condition during winter.

While condition also changed between sites of each coast, further studies are needed into

their morphologies, the environmental parameters, prey availability and abundance, and

sex and maturities.

1

2 


\section{3 'Problem'}

24 Research has never before looked at the condition of intertidal fish species, although such

25 analysis may aid in a better understanding of their ecology, ecosystem's health, and

26 ecosystem's productivity. Condition is related to reproductive success (Morgan, 2004),

27 whereby poor condition can result in lower fecundity and skipped spawning and therefore,

28 'good' fish condition may be indicative of optimal morphological adaptation in response to

29 environmental conditions, predator avoidance and prey capture. Poor conditions may

30 indicate anthropogenic or natural disturbance (Horn et al., 1999) and may also affect

31 ecosystem productivity. For example, in the North Sea (ICES area IVb) the shanny/common

32 blenny (Lipophrys pholis) have been shown (Pinnegar \& Platts, 2011) to contribute to the

33 diet of cod (Gadus morhua), and in the Barents Sea (I) and Greenland Sea (IIb), the long-

34 spined scorpion fish (Taurulus bubalis) have been found to contribute to the diets of

35 haddock (Melanogrammus aeglefinus) and G. morhua, respectively (Pinnegar \& Platts,

36 2011). The consumption of poor-conditioned specimens of such intertidal fish may result in

37 poorer condition of commercial fish, or may force a shift in their diet to combat such a

38 result, although the extent of the aftermath of such a scenario is not definitive.

39 The aim of this research is to determine whether Fulton's $\mathrm{K}$ condition factor could be used

40 to assess differences in the condition of intertidal fish species of the U.K., between

41 populations. Other determinants of assessing condition were considered, such as the

42 Relative Condition Factor (LeCren, 1951) and Relative Weight (Wege \& Anderson, 1978),

43 but dismissed. The former requires the use of a 'predicted, length-specific mean weight'

44 (Blackwell et al., 2000) per population, and a difference in this value would create

45 difficulties when comparing between populations. The latter requires defining a 'standard

46 weight' by taking the average weight from a high number of fish from different

47 populations. As this, similar to the other formulas, is usually applied to commercial fish, 
48 where huge ( $>28,000$ in the case of Morgan (2004), for example) abundances can be caught

49 and analysed with ease, determining what is a 'high' number of intertidal fishes is

50 debatable and so for caution, the Relative Weight formula was not applied.

51

52 'Study Area'

53 Filey Brigg (North Yorkshire; Fig. 1) protrudes east-west from the north end of Filey Bay. It

54 is approximately $1.5 \mathrm{~km}$ long, with a southern side $\left(54^{\circ} 13^{\prime} 00^{\prime \prime} \mathrm{N} 00^{\circ} 15^{\prime} 58^{\prime \prime} \mathrm{W}\right)$ sheltered

55 from northerly and westerly prevailing winds, and a northern side $\left(54^{\circ} 13^{\prime} 01^{\prime \prime} \mathrm{N}\right.$

$\left.5600^{\circ} 16^{\prime} 17^{\prime \prime} \mathrm{W}\right)$ exposed to the prevailing north-easterly winds.

57 Thornwick Bay (Fig. 1), also located in Yorkshire at $54^{\circ} 07^{\prime} 53^{\prime \prime} \mathrm{N} 00^{\circ} 06^{\prime} 51^{\prime \prime} \mathrm{W}$, features

58 regionally rare intertidal and subtidal chalk reefs, sea caves and sea-cliff vegetation

59 (Solandt and Lightfoot, 2010). It is $\sim 0.25 \mathrm{~km}$ shore length, and surrounded by chalk cliffs. A

60 freshwater stream runs onto the Bay from the south cliffs, which may influence local

61 community structure in the immediate vicinity.

62 The rocky shore at Penrhos (Anglesey; Fig. 1) is located at $53^{\circ} 18^{\prime} 13^{\prime \prime} \mathrm{N} 04^{\circ} 36^{\prime} 45^{\prime \prime} \mathrm{W}$. The

63 shore is $0.9 \mathrm{~km}$ long, with the busy ferry port of Holyhead $0.4-1.3 \mathrm{~km}$ to the northwest. The

64 shore is only exposed to the north, because it is protected by the mainland of Anglesey to

65 the east and south, and by Holyhead and the $2.4 \mathrm{~km}$-long breakwater to the west and

66 northwest, respectively.

67 Anglesey's rocky shore of Rhosneigr (Fig. 1) is $0.38 \mathrm{~km}$ long, situated at $53^{\circ} 13^{\prime} 06^{\prime \prime} \mathrm{N}$

$6804^{\circ} 30^{\prime} 36^{\prime \prime} \mathrm{W}$, and exposed to the west and the south, with limited shelter from the

69 Abberfraw headland to the south, but sheltered by sand-dunes on the landward side. 


\section{1 'Methods'}

72 The methodology is that of Barrett et al., (2013); specimen collection from all sites took

73 place over a week of spring tides in August 2010 (summer) and January 2011 (winter) and

74 fish were collected from small pools with the use of hand-nets (Gibson, 1999), and from

75 larger pools using home-made fish traps (Gibson, 1999). For minimal distress (Griffiths,

76 2000), captured fish were anaesthetised in a solution of clove oil in seawater (Horn et al.,

77 1999). Once all obvious activity ceased, the fish were placed in sample containers with a

78 solution of $4 \%$ formalin in seawater (Tucker and Chester, 1984) and taken to the

79 laboratory.

80 Specimens were left for 3 days in $4 \%$ formalin and then transferred to $70 \%$ ethanol for

81 another few days. Once the fixing process was complete, specimens were dried between

82 paper towels to remove excess ethanol, dissected and the entire digestive tract removed.

83 Then, the two more abundant specimen species (L.pholis and T.bubalis) were weighed (g)

84 on an electronic balance, to two decimal places, and their Total Lengths (TL) were recorded

$85(\mathrm{~mm})$ using callipers.

86 A limitation of using Fulton's condition factor is that, as different species have different

87 body shapes, the value ranges of $K$ will be different (Blackwell et al., 2000), thereby making

88 comparisons between different species inaccurate. Therefore, the two species were tested

89 separately. For each species, condition of specimens between seasons and sites were

90 tested using the non-parametric, Mann-Whitney $U$ test, as data was not normal and

91 columns were of unequal lengths (Dytham, 2011), using Minitab 14 software. This was

92 done to test whether between shores and seasons of a coast, the conditions of a given fish

93 species did not significantly differ. 
1

2

3

4

5

6

7

8

9

10

11

12

13

14

15

16

17

18

19

20

21

22

23

24

25

26

27

28

29

30

31

32

33

34

35

36

37

38

39

40

41

42

43

44

45

46

47

48

49

50

51

52

53

54

55

56

57

58

59

60
95 Table 1 displays the numbers of specimens used for condition analyses. It should also be

96 noted that $T$. bubalis were not present at Rhosneigr and Penrhos during the winter months,

97 and so seasonal comparisons at these sites could not be made for this species. The metric formula of Fulton's condition factor $(K)$ was adapted to:

99

$$
K=\left(\mathrm{W} / \mathrm{L}^{3}\right) \times 10^{5}
$$

100

Where $K=$ the condition factor, $\mathrm{W}=$ gutted weight $(\mathrm{g}), \mathrm{L}=$ Total length $(\mathrm{mm})$ and $10^{5}=$

101 scaling constant. The use of such scaling constants were used by previous authors (e.g.

102 Blackwell et al., 2000; Fernandez-Jover et al., 2007), and allows whole values of $K$ to be compared rather than having values $<1$, especially in the case of the small weights and sizes of many intertidal fish, such as those sampled in the current research. Length (total) was cubed, based on the assumption that as a fish grows, it does so in three dimensions: in its length, depth and breadth.

107

\section{'Results'}

109

L. pholis were in a significantly higher condition in summer (median $=10$, range $=52-543$ )

110 than winter $($ median $=9.7$, range $=48-80)$ in Filey (Mann Whitney U-test, $\mathrm{W}=2206.5, \mathrm{df}=$

$11150,29, \mathrm{P}<0.05$ ) and the same pattern was shown at Thornwick Bay (summer median $=11$,

112 range $=61-845 ;$ winter, median $=9.6$, range $=56-85):$ Mann Whitney U-test, $\mathrm{W}=2132, \mathrm{df}=$ $11350 \& 23, P=<0.001)$.

114 T. bubalis were also in significantly better condition during summer at Thornwick Bay

115 (summer median $=17$, range $=100-178 ;$ winter , median $=15$, range $=80-138):($ Mann

116 Whitney U-test, $\mathrm{W}=618, \mathrm{df}=23 \& 20, \mathrm{P}<0.05)$, but no significant difference was found at

117 Filey between seasons. 
118 On the west coast, $T$. bubalis were in significantly better condition at Rhosneigr, during the

119 summer $($ median $=21$, range $=15-429)$ than Penrhos, during the summer $($ median $=14$,

120 range $=85-143)$, (Mann Whitney U-test, $\mathrm{W}=252, \mathrm{df}=15 \& 10, \mathrm{P}<0.05)$. In comparison, this

121 condition of L. pholis, and T. bubalis, did not differ significantly between summer and

122 winter at either of the two shores. Conditions of all remaining shores and seasons between

123 the two fishes, proved non-significant.

124

125 'Discussion'

126 The research has identified Fulton's $\mathrm{K}$ as a suitable condition factor for assessing and

127 comparing the condition of intertidal fish species, and this study could act as a baseline for

128 prospective studies on the same fish species.

129 The study suggests that as L. pholis did not differ in condition between seasons around the 130 Anglesey coast, it could be assumed that the Welsh population is maintaining a phenotype 131 which is allowing better ecological success than the English population, as their condition is 132 not hindered during the adverse winter season. When the larger specimens of intertidal 133 fish migrate offshore, either to forage or conforming to the 'Pool Load Capability' 134 hypothesis of Monteiro et al., 2005, from a commercial fisher's perspective, this may be of 135 ecological importance. If the findings of Pinnegar and Platts (2011) are also true of Welsh, 136 Irish Sea, commercial fish species, and the intertidal fish species contribute highly to their 137 diet, the commercial species may be in a 'good' condition as a result, and would therefore 138 fetch a greater market value.

139 It should also be considered that the 'good' condition of Anglesey intertidal fish may be 140 indicative of greater prey availability and more optimal environmental conditions. This is 
1

2

3

4

5

6

7

8

9

10

11

12

13

14

15

16

17

18

19

20

21

22

23

24

25

26

27

28

29

30

31

32

33

34

35

36

37

38

39

40

41

42

43

44

45

46

47

48

49

50

51

52

53

54

55

56

57

58

59

60
141 further implied by both species never being in the better condition during the winter

142 season; only ever the same condition, or poorer.

143 To identify the potential cause(s) for the conditions determined by the current study, and

144 to explain why English fish did not maintain as good a condition as the Welsh fish, future

145 research would ideally need to incorporate fish morphologies (Webster et al., 2011);

146 environmental parameters (Wilson (1990 \& 2011); prey availability and abundance

147 (Armstrong \& McGehee, 1980); and sex and maturities (Lloret et al., 2002).

148

149 Summary

150 As contributors to the diet of commercial fish species such as cod (Gadus morhua) and as

151 important prey items of the sea otter (Enhydra lutris), the current study could be used to

152 help predict populations of said predators. Where intertidal fish condition is seen to be

153 'poor,' it may be predicted that predator condition/health (with particular regard to $E$.

154 lutris, which consumes T. bubalis in large quantities) may deteriorate and may cause a

155 trade-off between conserving energy and foraging less (thus reducing energy gains) and

156 increasing foraging time to consume more of the low-conditioned intertidal fish and

157 spending more energy in the process. The study could be combined with the conceptual

158 model of fish coexistence by Barrett et al., (2014), to help managers establish and maintain

159 a diverse and healthy population of intertidal fishes.
160

161

162

163 
165 Thanks and gratitude to Dr Andy Payne and Dr Jim Ellis, for giving their time to improve the

166 original manuscript, and to Dr Tim Grabowski, for past correspondence regarding fish

167 condition.

168

169 References cited

170 Armstrong, R.A., McGehee, R. (1980) Competitive Exclusion. American Naturalist, 115, $171 \quad 151-170$.

172

173 Barrett, C.J., Johnson, M.L., Hull, S.L. (2013) Diet as a mechanism of coexistence between

174 intertidal fish species of the U.K. Journal of Fish Biology, (IN REVIEW).

175

176 Barrett, C.J., Johnson, M.L., Hull, S.L. (2014) Intertidal fish of the U.K.: Mechanisms of

177 coexistence. Marine Ecology, (IN REVIEW).

178

179 Blackwell, B.G., Brown, M.L., Willis, D.W. (2000) Relative weight (Wr) status and current use

180 in fisheries assessment and management. Reviews in Fisheries Science, 8, 1-44.

182 Crisp, D.J. (1964) The effects of the Severe Winter of 1962-1963 on Marine Life in Britain.

183 Journal of Animal Ecology, 33, 165-210. 
1

2

3

4

5

6

7

8

9

10
185 Dytham, C. (2011) Choosing and using Statistics: A Biologist's Guide: Third Edition, Wiley-

186 Blackwell, Sussex, U.K.: 23-29 pp.

187

188 Fernandez-Jover, D., Jimenez, J,A.L., Sanchez-Jerez, P., Bayle-Sempere, J., Casalduero, F.G., 189 Lopez, F.J.M., Dempster, T. (2007) Changes in body condition and fatty acid composition of 190 wild Mediterranean horse mackerel (Trachurus mediterraneus, Steindachner, 1868)

191 associated to sea cage fish farms. Marine Environmental Research, 63, 1-18.

193 Horn, M.H., Martin, K.L.M., Chotkowski, M.A. (1999) Intertidal Fishes: Life in Two Worlds, 194 Academic Press, San Diego: 118-145 pp.

195

196 Hull, S.L. (1999) Comparison of tidepool phytal ostracod abundance and assemblage 197 structure on three spatial scales. Marine Ecology Progress Series, 182, 201-209.

198

199 LeCren, E. D. (1951) The Length-Weight Relationship and Seasonal Cycle in Gonad 200 Weight and Condition in the Perch Perca fluviatilis. Journal of Animal Ecology, 20, 201201219.

203 Lloret, J., Gil de Sola, L., Souplet, A., Galzin, R. (2002) Effects of large-scale habitat variability 204 on condition of demersal exploited fish in the north-western Mediterranean. ICES Journal 205 of Marine Science, 59, 1215-1227. 
207 Monteiro, N.M., Quinteira, S.M., Silva, K., Vieira, M.N., Almada, V.C. (2005) Diet preference

208 reflects the ontogenetic shift in microhabitat use in Lipophrys pholis. Journal of Fish

209 Biology, 67, 102-113.

210

211 Morgan, J.M. (2004): The relationship between fish condition and the probability of

212 being mature in American plaice (Hippoglossoides platessoides). ICES Journal of Marine

213 Science, 61, 64-70.

214

215

216 Pinnegar, J.K., Platts, M. (2011): DAPSTOM - An Integrated Database \& Portal for Fish

217 Stomach Records. Version 3.6. Centre for Environment, Fisheries \& Aquaculture Science,

218 Lowestoft, UK.: 35 pp.

219

220

221 Webster, M.W., Atton, N., Hart, P.J.B., Ward, A.J.W. (2011): Habitat-Specific Morphological

222 Variation among Threespine Sticklebacks (Gasterosteus aculeatus) within a Drainage Basin.

223 PLOS. ONE. 6, e21060.

224

225

226 Wege, G.W., Anderson, R.O. (1978) Relative Weight (Wr) a new index of condition for

227 largemouth bass. In: Willis, D.W., Guy, C.S. (1991): Development and evaluation of a

228 Standard Weight (Ws) equation for yellow perch. North American Journal of Fisheries

229 Management, 11, 374-380.

230

Marine Ecology 
1

2

3

4

5

6

7

8

9

10

11

12

13

14

15

16

17

18

19

20

21

22

23

24

25

26

27

28

29

30

31

32

33

34

35

36

37

38

39

40

41

42

43

44

45

46

47

48

49

50

51

52

53

54

55

56

57

58

59

60
231 Wilson, J.B. (1990) Mechanisms of species coexistence: twelve explanations for

232 Hutchinson's 'paradox of the plankton': evidence from New Zealand plant communities.

233 New Zealand Journal of Ecology, 13, 17-42.

234

235

Wilson, J.B. (2011) The twelve theories of co-existence in plant communities: the doubtful,

236 the important and the unexplored. Journal of Vegetation Science, 22, 184-195.

237

238

239

240

241

242 around the Anglesey coast (Barrett et al., 2013). 
252

253

254

10

11

12

13

14

15

16

17

18

19

20

21

22

23

24

25

26

27

28

29

30

31

32

33

34

35

36

37

38

39

40

41

42

43

44

45

46

47

48

49

50

51

52

53

54

55

56

57

58

59

60

Marine Ecology 
1

2

3

4

5

6

7

8

9

10

11

12

13

14

15

16

17

18

19

20

21

22

23

24

25

26

27

28

29

30

31

32

33

34

35

36

37

38

39

40

41

42

43

44

45

46

47

48

49

50

51

52

53

54

55

56

57

58

59

60

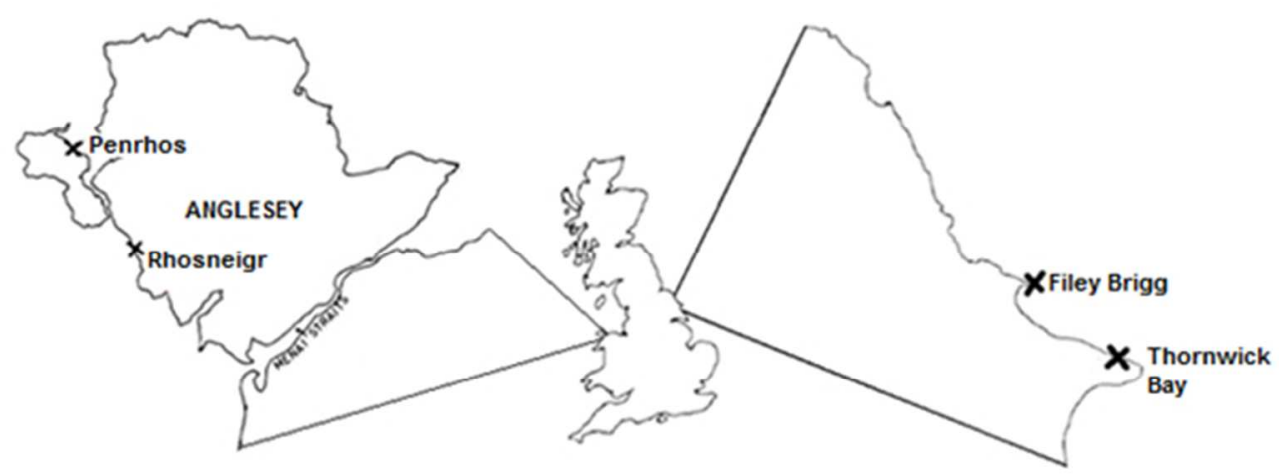

$161 \times 62 \mathrm{~mm}(96 \times 96 \mathrm{DPI})$ 
Table 1: Numbers of specimens used for condition analysis

8 